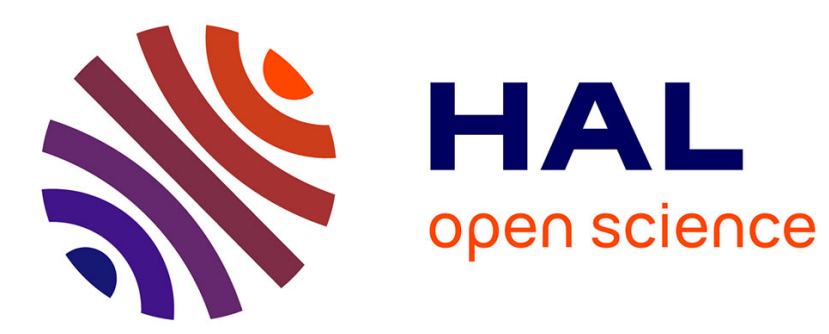

\title{
LIGHT SCATTERING FROM CHARGE-DENSITY WAVES
}

E. Steigmeier, D. Baeriswyl, G. Harbeke

\section{To cite this version:}

E. Steigmeier, D. Baeriswyl, G. Harbeke. LIGHT SCATTERING FROM CHARGEDENSITY WAVES. Journal de Physique Colloques, 1976, 37 (C4), pp.C4-177-C4-178. 10.1051/jphyscol:1976429 . jpa-00216543

\section{HAL Id: jpa-00216543 https://hal.science/jpa-00216543}

Submitted on 1 Jan 1976

HAL is a multi-disciplinary open access archive for the deposit and dissemination of scientific research documents, whether they are published or not. The documents may come from teaching and research institutions in France or abroad, or from public or private research centers.
L'archive ouverte pluridisciplinaire HAL, est destinée au dépôt et à la diffusion de documents scientifiques de niveau recherche, publiés ou non, émanant des établissements d'enseignement et de recherche français ou étrangers, des laboratoires publics ou privés. 


\title{
LIGHT SCATTERING FROM CHARGE-DENSITY WAVES
}

\author{
E. F. STEIGMEIER, D. BAERISWYL and G. HARBEKE \\ Laboratories RCA Ltd, Zürich, Switzerland
}

\begin{abstract}
Résumé. - On présente de nouvelles expériences de diffusion de lumière par des excitations d'ondes de densité de charge dans des matériaux à une et deux dimensions. En particulier, on discute la dépendance en température des modes en relation avec la transition Peierls.
\end{abstract}

Abstract. - New light scattering experiments on CDW excitations in quasi-one- and twodimensional materials are reported. In particular, the temperature dependence of the modes is discussed with respect to the Peierls transition.

Static (or at least quasi-static) periodic distortions arising from the Peierls instability are known to occur both in one- and two-dimensional materials. Since these distortions are accompanied by a spatially periodic redistribution of electronic charge they are usually called charge-density waves (CDW). The dynamic oscillations around this distorted ground-state are known as the amplitude and phase mode of the CDW. In inelastic neutron scattering experiments these excitations manifest themselves as strong anomaly at twice the Fermi wave vector. However, the resolution function of the neutron spectrometer does not allow for a determination of definite eigenfrequencies at $2 k_{\mathrm{F}}$ [1].

Light scattering offers an alternative way of observing CDW modes since the static distortion of periodicity $2 k_{F}$ relaxes the $k$-selection rule, and since the wave vector resolution is much better than in a neutron scattering experiment. The coupling of the light to the $2 k_{\mathrm{F}}$ excitations is proportional to the amplitude of distortion and thus, light scattering from CDW modes should disappear at the Peierls transition temperature $T_{\mathrm{p}}$. Furthermore, theory predicts a softening of these modes by approaching $T_{\mathrm{p}}$ from below.

By means of Raman scattering we did observe $\mathrm{CDW}$ excitations in both the quasi one-dimensional (KCP) and two-dimensional case $\left(2 \mathrm{H}-\mathrm{TaSe}_{2}\right)$. In KCP a distinct line was observed at about $44 \mathrm{~cm}^{-1}$ and attributed to the amplitude mode [2], in good agreement with the corresponding phase mode extracted from infrared experiments [3]. This line was detected at all temperatures (the coupling coefficient decreased only slightly with increasing temperature). Furthermore, no softening but even a hardening of this mode was observed together with a strong increase in damping. This clearly indicates that no Peierls transition (in the structural sense) takes place in KCP at any accessible temperature. Additional experiments on deuterated samples showed a large isotope effect [4] which suggests that the CDW excitations of the Ptchains are coupled to the intramolecular vibrations of water molecules located in between the chains. Thus the « one-dimensional metal» KCP seems to be more three-dimensional in nature than commonly assumed.

$2 \mathrm{H}$-TaSe ${ }_{2}$ is a layered material which does undergo phase transitions associated with planar distortions of the lattice [5]. Below $122 \mathrm{~K}$ it develops a near-threefold incommensurate superlattice which becomes commensurate with the original lattice at $90 \mathrm{~K}$. The Raman spectrum shows several low-lying lines at low temperatures [6]. At least two of them (at 49 and $82 \mathrm{~cm}^{-1}$ ) change drastically in intensity, position and width by approaching the transition temperatures and thus are attributed to CDW excitations. In particular, both lines soften with increasing temperature as is seen in figure 1. The frequency of the lower mode tends to zero towards $122 \mathrm{~K}$ with an exponent of about $1 / 3$ whereas the higher line seems to be connected with the transition at $90 \mathrm{~K}$. The width of both lines increases strongly with temperature on approaching $122 \mathrm{~K}$ and $90 \mathrm{~K}$, respectively, whereas the coupling coefficient (which is proportional

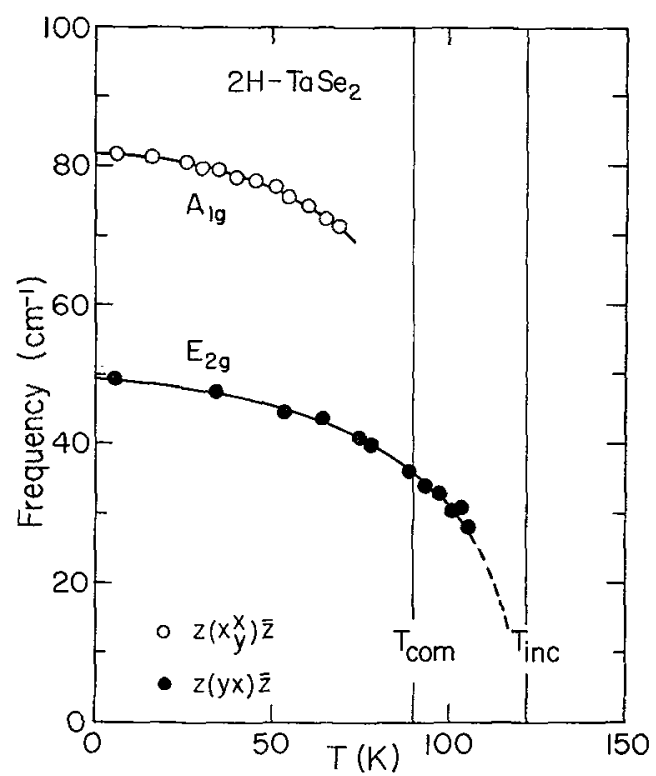

FIG. 1. - Frequency of the CDW modes versus temperature. 
to the order parameter) decreases and is zero in the undistorted phase $[6,7]$.

Thus in both the one- and two-dimensional case, Raman scattering experiments have given detailed information about the dynamics of CDW's. The most significant new observation is the softening of CDW modes near the Peierls transition in the layered material.

Acknowledgements. - We gratefully acknowledge G. Scheiber and F. J. Di Salvo for providing the crystals.

\section{References}

[1] Carneiro, K., Shirane, G., Werner, S. A. and Kaiser, S., Phys. Rev. B 13 (1976) 4258.

[2] Steigmeier, E. F., Loudon, R., Harbeke, G., Auderset, H. and SCHEIBER, G., Solid State Commun. 17 (1975) 1447.

[3] Brüesch, P., Strässler, S. and Zeller, H. R., Phys. Rev. В 12 (1975) 219.

[4] Steigmeier, E. F., Baeriswyl, D., Harbeke, G., Auder-
SET, H. and Schetber, G., Solid State Commun. 20 (1976) to be published.

[5] Moncton, D. E., Axe, J. D. and Di Salvo, F. J., Phys. Rev. Lett. 34 (1975) 734.

[6] Steigmeier, E. F., Harbeke, G., Auderset, H. and Di Salvo F. J., Solid State Commun. 20 (1976) to be published.

[7] Fuller details about the experiments are given in ref. [2] and [4] for $\mathrm{KCP}$ and in ref. [6] for $2 \mathrm{H}-\mathrm{TaSe}_{2}$. 